Kleidung durch, dafs sie bis ins Mark der Knochen zu dringen schien. Trotzdem zog vormittags, gegen den heftigst wehenden Wind anfliegend, eine ganze Anzahl von Lerchenschwärmen; sie flogen dabei kaum über Meterhöbe über den Erdboden weg, folgten jeder Senkung und Hebung des ganz schwachwelligen Landes, bielten aber unbeirrt ihre Zugrichtung inne; der Zug fand zwischen $8^{\circ}$ und $10^{\circ}$ vormittags statt, und in dieser Zeit folgte ein Schwarm dem andern.

Ich habe die vorstehend geschilderten Zugbeobachtungen in einer Zeit gemacht, in der ich wie fast alle anderen unter dem entsetzlichsten Druck der kriegerischen und politischen Ereignisse gelebt habe, wo das Herz über die Not des Vaterlandes schwer bedrückt, die Seele bekümmert war bis in den Tod und jede Freude aus dem Geist geschwunden schien. Es waren Tage so scbwer, wie ich sie nicht noch einmal in meinem Leben durchkosten möchte. In dem Jammer und Elend dieser Zeitlänfte hat mich nur die täglicho Beschäftigung mit der Natur und die Beobachtung ihrer Lebensäufserungen gestärkt und erquickt; Herz und Sinn belebten sich und richteten sich auf, wenn sie sich der Betrachtung eines der gewaltigsten Naturphänomene zuwandten; nie habe ich so sehr als in diesen Zeiten empfunden, welchen Trost die Natur ihren Jüngern zu spenden vermag.

\title{
Paul Robert Kollibay $\uparrow$.
}

Am 5. November 1919 durcheilte die fast anglaubliche Trauerkunde unser Land, die uns den plötzlichen Tod unseres so allgemein verehrten und geachteten Vizepräsidenten Justizrat Paul Robert Kollibay anzeigte.

Tief gebeugt steht das Heer der deutschen Ornithologen an der Bahre dieses prächtigen Mannes, der es verstanden hat, durch eisernen Fleifs Erfolge zu erzielen, die ihm einen gebührenden Platz unter den Ersten unserer Ornithologen für alle Zeit sichern. 1869 begann Kollibay seine Ausbildung auf der Volksschule zu Neustadt 0./S., woselbst er auch von 1873 bis 1882 das Gymnasium besuchte. Während dieser Schulzeit wurde in ihm durch den Verkehr mit dem Sohn des bekannten Ornithologen Dr. Kutter die Liebe zur Vogelwelt entfacht, wozu die herrliche bewaldete Umgebung Neustadts die schönste Gelegenheit bot.

1879 machte er seine ersten Aufzeichnungen, die den Grund zu dem später erschienenen Werk „Die Vögel der Preufsischen Provinz Schlesien" legten. In demselben Jahre begann er mit seiner für Schlesien so bedeutungsvollen Balg- und Eiersammlung.

Seinem sehnlichsten Wunsch, Naturwissenschaften zu studieren, konnte er leider nicht nachkommen, er wählte daher als Brot- 
studium Jura, ging nach Breslau und studierte daselbst bis 1885 . Im folgenden Jahr wird er Referendar und 1890 besteht er den Assessor" mit "gut". Seino bedeutenden juristischen Kenntnisse verwertete Kollibay als Rechtsanwalt, als welchen wir ihn 1891 in Neifse wiederfinden. 1897 bekommt er das Notariat, 1910 wird er Justizrat und 1917 Mitglied des Vorstandes der Anwaltkammer. Neben seiner Riesenpraxis fand er noch Zeit, als Neirser Bürger für seine Stadt Bedeutendes zu leisten, die ilın 1916 zum Stadtverorduetenvorsteher wählte.

Neben diesen vielen gewissenbaft erfüllten Pfichten ruhto keinen Augenblick seine ornithologische Tätigkeit. Sein Hauptverdienst ist das Werk , die Vögel der Preursischen Provinz Schlesien", welches 1906 erschien und welchem 1909 Nachträge im Orn. Jahrb. und 1915 weitere Nachträge in Reichenow's Ornithol. Monatsberichten folgten. Wer dieses mit unendlichem Fleifs und mit noch viel grörserer Gewissenhaftigkeit zusammengetragene Werk durchblättert, wird zu der Überzeugung kommen, dars der Verfasser keineswegs nur Balgornithologe war. Hiervon konnte sich auch jeder überzeugen, der das Glück hatte, mit dem Verstorbenen durch die von ihm so heifs geliebte Natur zu wandern; es entging ihm nichts! Bald wurde or Mitarbeiter an dem Journal für Ornithologie. Von diesen Arbeiten wären hervorzuhebeu „Die paln̈arktischen Apodiden" für die sich Kollibay ganz besonders interessierte und vou denen Tschusi Bewohner der Insel Curzola subspezifisch trenate und Kollibay zu Ehron Apus apus kollibayi benannte.

Ferner interessieren zwei Aufsätze „Eine vergleichende Besprechung der rheinischen und schlesischen Vogelfauna" und "die Vogelfauna der Boche di Cattaro". Ungeheuer viele Aufsïtze, Bemerkungen u. dergl. meist übèr schlesisches Material, so besonders über den 'Tannenbäher' finden sich in den schlesisclen Zeitungen zerstreut vor.

Sein Ruf ging bald über die Provinz Schlesien hinaus, und 1906 nennt er sich schon ,Ausschussunitglied der Deutschen Ornithol. Gesellschaft, Member of the British Ornithologists'Union". Bald darauf wurde er Vizepräsident uuserer Gesellschaft.

1911 ernennt ihn dio Naturforschende Gesellschaft zu Görlitz zu ihrem korrespondierenden Mitglied.

Den grörsten Dank aber schulden ihm die schlesischen Ornithologen, denn Kollibay war. es, der 1904 das Interesse für die heimiscbe Vogelwelt neu belebte, indem er durch die Gründung des Vereins schlesischer Ornithologen einen Zusammenschlufs aller Interessenten herbeiführte, der, wie die niedergeschriebenen Berichte beweisen, einen aufserordentlichen günstigen Erfolg zeitigte. Kollibay wurde Vorsitzender des Vereins, und durch seine weitgehenden Beziehungen blieb die schlesische Ornithologie auf dem Laufenden und zog immer mehr Vogelfreunde an sich. 
Seit 1896 entfloh er alljäbrlich einmal dem dumpfen Aktenstaub, um einige Wochen seinen geliebten Studien zu leben. Wir finden ihn dann auf den Mittelmeerhalbinseln, in der Schweiz oder an den nordischen Küsten u. s. w., wo er eifrig beobachtend und sammelnd sein Wissen und seine paläarktische Balg- und Eiersammlung vergrörsert. Mit allen bedeutenden Ornithologen des In- und Auslandes stand er in eifrigem Brief- und Tauschverkehr, und mitten in dieser riesenhaften Tätigkeit ereilt ihn plötzlich der unerbittliche Tod! Die letzten Lebenstarre noch liefsen das Mafs der Freude überlaufen, denn der verloren geglaubte Sohn kehrte aus der bitteren Gefangenschaft heim, und seine Tochter feierte Hochzeit! Das waren die melodischen Schlufsakkorde seines arbeitsreichen und frommen Lebens; und als wir ihn bei tiefem Schnee hinaustrugen auf den Jerusalemer Kirchbof zu Neifse und ihn der kühlen Erde zur ewigen Ruhe übergaben, da zogen über das offene frische Grab Saatkrähen in ihrem Trauergewand - - sie brachten ihrem Neister die letzten Grülse seiner Lieblinge! E. Dresoher.

\section{Die Avifanna des westlichen Pripjet-Sumpfes im Liehte der Forsehung dentscher Ornithologen in den Jahren 1915-1918.}

\section{Von O. Graf Zedutz.}

\section{(Hierzu Tafel 1 and 2.)}

Vor dem Kriege dürften nicht viele Deutsche den PripjetSumpf, vielfach auch weniger glücklich Rokitno-Sumpf genannt, die "Polesje" der Russen, anders als dem Namen nach geliannt haben. Dem Touristen fiel es ganz gewifs wicht ein, sich in diese unwegsame Gegend zu verirren, der Händler und Kaufmann fand auch kein günstiges Feld der Tätigkeit, denn trotz des Reichtums an hocbwertigem $\mathrm{Holz}$ war der Transport desselben in Flössen auf dem sehr langen Wasserwege die Schara und den Njemen abwärts so teuer und unsicher, dils nicht viel dabei zu verdienen war. Die Landwirtschaft erst gar stand auf sehr tiefer Stufe und lieferte kaum der spärlichen Bevölkerung genüøend Nabrung, von Export ihrer Erzeugnisse war keine Rede. Auch der Naturforscher, einschliefslich der russischen Zoologen, reiste eher nach Transkaspien und bis ins fernste Ost-Turkestan als in die im Herzen des Reiches liegende Polesje. „Nach Pinsk geschickt werden" bedeutete im russischen Vollismund soviel als, ,in den weltentlegensten trostlosesten Verbannungsort gehen, der jenseits jeglicher Kultur liegt". Unsre wissenschaftliche Literatur aller Sprachen bietet uns denn auch so gut wie gar nichts über dieses doch recht interessante Gebiet bis zum Jahre 1915. Als 